\title{
VICENTE CARDUCHO Y LA HERMANDAD DEL REFUGIO EN MADRID: ENCARGOS ARTÍSTICOS Y PROYECCIÓN CORTESANA*
}

\author{
DAVID MALlÉn HerRÁIZ ${ }^{1}$ \\ Universidad Complutense de Madrid
}

\begin{abstract}
El viernes 29 de diciembre de 1628, la junta semanal celebrada por la Santa, Pontificia y Real Hermandad del Refugio y Piedad de Madrid aceptaba el ingreso como hermano del pintor de origen florentino Vicente Carducho. Esta fecha marca el inicio de un interesante e inexplorado vínculo entre el artista y la congregación religiosa, para la cual ofrecerá su colaboración y entre cuyas peticiones destaca la intervención en un desconocido retablo enviado desde Nápoles para presidir el altar mayor de la desaparecida iglesia de Nuestra Señora de la Concepción. Tales gestiones suponen una valiosa fuente de información que aporta nuevos datos sobre la actividad del pintor y la consolidación de una fructífera red de contactos recogida en su tratado Diálogos de la pintura.
\end{abstract}

Palabras clave: siglo XVII; Madrid; Hermandad del Refugio; Vicente Carducho; Diálogos de la pintura; Enríquez de Ribera; retablo mayor; Massimo Stanzione.

\section{VICENTE CARDUCHO AND THE HERMANDAD DEL REFUGIO IN MADRID: ARTISTIC COMMISSIONS AND COURT REPERCUSSION}

On Friday $29^{\text {th }}$ December 1628, the assembly of the Santa, Pontificia y Real Hermandad del Refugio y Piedad of Madrid admitted the Florentine painter Vicente Carducho as a member. This event marks the beginning of an interesting and previously unexplored link between the artist and the religious congregation to which he offered his labors. Among the tasks assigned to the painter is his outstanding work on a little known altarpiece sent from Naples for the high altar of the lost Church of Nuestra Señora de la Concepción. Such contributions are a valuable source of new information about the painter's activities and his network of contacts with the rest of the Brotherhood members, as reported in his treatise Diálogos de la Pintura.

Key words: $17^{\text {th }}$ century; Madrid; Hermandad del Refugio; Vicente Carducho; Diálogos de la pintura; Enríquez de Ribera; altarpiece; Massimo Stanzione.

Cómo citar este artículo / Citation: Mallén Herráiz, David (2021) "Vicente Carducho y la Hermandad del Refugio en Madrid: encargos artísticos y proyección cortesana”. En: Archivo Español de Arte, vol. 94, núm. 375, Madrid, pp. 233-246. https://doi.org/10.3989/aearte.2021.14.

\footnotetext{
* Este artículo está dedicado a la memoria del Dr. D. Vicente Lleó Cañal, catedrático de la Universidad de Sevilla. Su publicación no habría sido posible sin las facilidades ofrecidas por los hermanos de la Santa, Pontificia y Real Hermandad del Refugio y Piedad de Madrid, en especial a la favorable disposición del Hermano Mayor y de don Diego López por abrirme las puertas de su archivo. También doy las gracias a doña María Teresa Cruz Yábar, directora de mi tesis doctoral, por las correcciones sugeridas en el texto.

1 damallen@ucm.es / ORCID iD: https://orcid.org/0000-0002-3634-3262.
} 
Desde su fundación por el padre jesuita Bernardino de Antequera en $1615,{ }^{2}$ la Santa, Pontificia y Real Hermandad del Refugio y Piedad de Madrid ha constituido una de las congregaciones benéficas de mayor trascendencia en la historia de la corte. Su intensa y eficiente labor caritativa sería determinante en la mejora de la calidad de vida de muchos de los pobres desvalidos, enajenados mentales, niños huérfanos y mujeres perdidas que deambulaban por las calles de la villa. Hace años que tan necesarios menesteres han alentado a los investigadores a estudiar su papel institucional desde el punto de vista sanitario, económico y social durante el Antiguo Régimen, ${ }^{3}$ así como a divulgar el rico patrimonio material conservado en la iglesia de San Antonio de los Alemanes, sede oficial de la Hermandad desde el año $1702 .{ }^{4}$

Sin embargo, este último dato - que ha desviado la atención de los historiadores hacia esta joya arquitectónica del Barroco madrileño - pone en evidencia la vasta laguna historiográfica que atañe a las empresas constructivas y patrimoniales acometidas por el Refugio durante sus primeros ochenta y siete años de existencia, por lo que sus avatares artísticos aún permanecen ocultos entre los papeles de su archivo. Del mismo modo, los sucesivos cronistas han destacado la presencia de algunos de sus miembros más ilustres como los monarcas Felipe IV y Carlos II, el conde-duque de Olivares, el cardenal Giovanni Battista Pamphili - futuro Papa Inocencio X - o el dramaturgo Pedro Calderón de la Barca, ${ }^{5}$ sin prestar demasiada atención a la identidad del resto de hermanos que participaron activamente en los ejercicios piadosos y administrativos de la congregación a lo largo del siglo XVII.

De hecho, una breve consulta bibliográfica - derivada del hallazgo de una carta remitida por el virrey de Nápoles en 1631 — nos ha llevado a conocer un apunte publicado por el cronista José del Corral que ha pasado totalmente desapercibido: el ingreso como hermano del pintor y tratadista Vicente Carducho (h.1576-1638). ${ }^{6}$ Ratificando la veracidad de este dato, hemos podido localizar el asiento donde consta la firma y rúbrica del artista [fig. 1], que fue miembro de la congregación desde finales de 1628 hasta su muerte diez años después. ${ }^{7}$

Sin embargo, este hecho trasciende de lo meramente anecdótico, pues a través de los sucesivos libros de gobierno se puede hacer un seguimiento bastante completo de la participación del pintor en los ejercicios caritativos y en las demandas artísticas establecidas por las juntas semanales cada viernes, lo que supone el hallazgo de una importante fuente de información que nos permite aportar nuevas referencias sobre la trayectoria y personalidad del pintor.

\section{Ocupaciones benéficas de Vicente Carducho como hermano}

El 29 de diciembre de 1628, al finalizar la Junta general presidida por el primer consiliario Juan Chacón Ponce de León en ausencia del Hermano Mayor, ${ }^{8}$ se daba por reconocido el recibimiento de Vicente Carducho como hermano, siendo inscrito con el número 523. En el registro que firmó

\footnotetext{
${ }^{2}$ La filial madrileña de la Hermandad del Refugio, dependiente de otra creada anteriormente en Toledo, fue fundada el 15 de marzo de 1615 por Bernardino de Antequera ( $\uparrow 1634)$, Pedro Lasso de la Vega (†1621) y Juan Jerónimo Serra $(\dagger 1642)$, aunque la primera acta de reunión de la que se tiene constancia está fechada el 25 de enero de 1618. (Corral, 1998: 75).

3 Respecto a la historia institucional de la Hermandad, véase: Cossío y Gómez-Acebo, 1915; Callahan, 1980; Tepa, 1995; Corral, 1998; Moralejo Ortega, 2016.

${ }^{4}$ Es importante subrayar que la iglesia de San Antonio de los Alemanes —originariamente, iglesia del Hospital de San Antonio de los Portugueses - no tiene nada que ver con el Refugio hasta que el rey Felipe V cede la propiedad de su patronato, bienes y rentas a la congregación en 1702. En cuanto a la historia patrimonial del edificio, véase: Pajarón Sotomayor, 1977; Arranz Otero / Gutiérrez Pastor, 1999; Fernández Peña, 2006; Gómez Laínez, 2015.

${ }^{5}$ Callahan, 1980: 29.

${ }^{6}$ Corral, 1998: 67.

${ }^{7}$ Libro de Hermanos, 1615-1703, Archivo de la Santa, Pontificia y Real Hermandad del Refugio y Piedad de Madrid (AHRM), legajo 128-1, 247.

${ }^{8}$ Entre 1622 y 1629 el cargo de Hermano Mayor fue ocupado por Fernando Fernández de Córdoba y Cardona, abad de Rute e hijo del V duque de Sessa: Callahan, 1980: 179.
} 


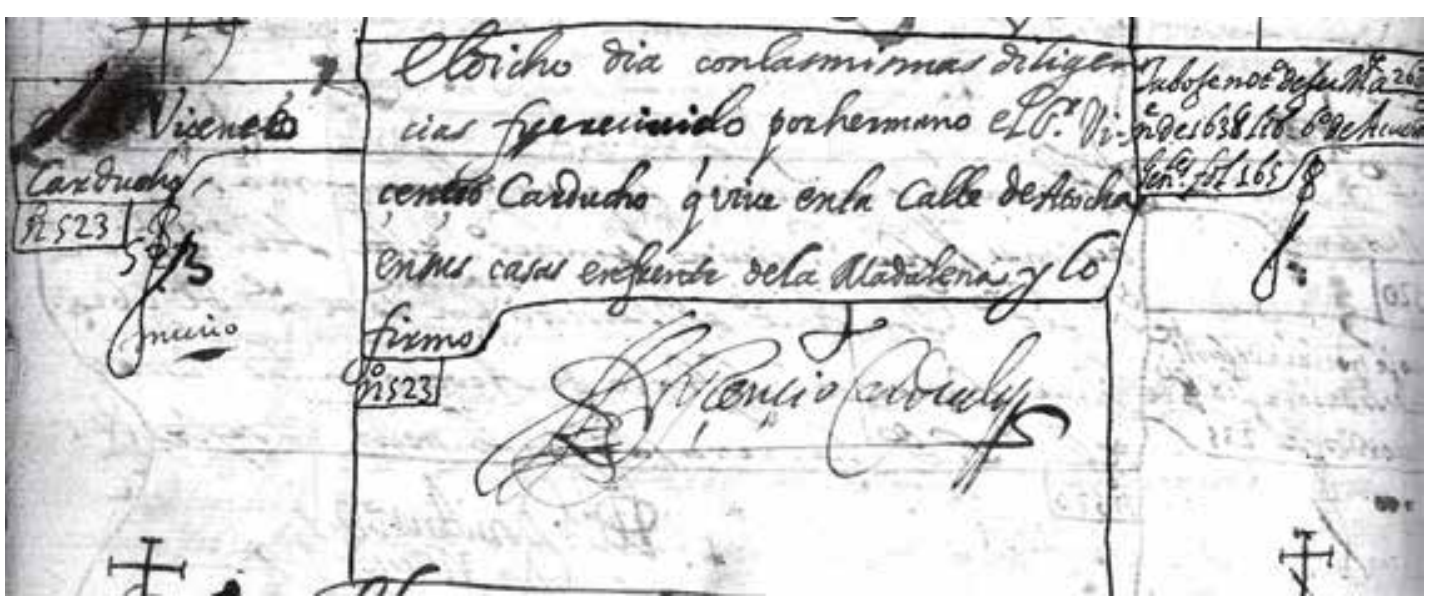

Fig. 1. Registro y firma de ingreso del pintor Vicente Carducho, 29 de noviembre de 1628, (AHRM) Legajo 128-1, 247 (Fot. AHRM).

de su puño y letra ese mismo día no se hace mención alguna a su oficio de pintor, tan solo a la ubicación de su residencia "en la calle de Atocha [...] enfrente de la Madalena" y a la recepción de la noticia de su deceso el 26 de noviembre de 1638.

En el momento de su ingreso, Carducho era un experimentado artista que contaba con unos cincuenta y dos años de edad. ${ }^{9}$ Hacía más de cuarenta que había llegado a España desde su Florencia natal acompañando a su hermano mayor —el también pintor Bartolomé Carducho- para que este participase como ayudante del maestro italiano Federico Zuccaro en la campaña decorativa del Real Monasterio de San Lorenzo del Escorial. ${ }^{10}$ Durante el reinado de Felipe III, el artista consolidaría su prestigio al encabezar numerosos encargos reales, nobiliarios y eclesiásticos, si bien sería con el gobierno de Felipe IV cuando se vería inmerso en tres de sus más importantes proyectos con los que acrecentaría significativamente su fama: la ejecución del ciclo pictórico para la Cartuja del Paular desde 1626, ${ }^{11}$ la finalización de su tratado Diálogos de la pintura en 1633 y la participación en la decoración del Salón de Reinos del Palacio del Buen Retiro en 1634. ${ }^{12}$

Aunque la entrada del florentino en el Refugio puede resultar singular, pues no localizamos entre los hermanos a otros pintores con una reputación semejante, lo cierto es que sus intenciones parecen responder a cuestiones tanto personales como profesionales. En primer lugar, Carducho ya era miembro de otras tres congregaciones madrileñas como la Venerable Orden Tercera de San Francisco, la Cofradía del Santísimo Sacramento y la Cofradía del Santísimo Cristo de la $\mathrm{Fe},{ }^{13}$ para las que colaboraría en las tareas corporativas y participaría en alguno de sus proyectos decorativos,${ }^{14}$ además de legar a todas ellas diferentes mandas en sus últimas voluntades testamentarias. ${ }^{15}$ Quizás, estos precedentes sirvieron para que el pintor atestiguase el cumplimiento de un cierto grado de responsabilidad caritativa y servicial que encajaría perfectamente con las empresas asistenciales de la Hermandad del Refugio, lo cual podría haber favorecido su admisión.

${ }^{9}$ A pesar de la abundancia de estudios pormenorizados acerca de los proyectos y encargos acometidos por Vicente Carducho, no existe una monografía completa y actualizada que recoja su biografia y trayectoria. No obstante, como publicaciones más ampliamente centradas en su figura y obra, véase: Carducho, 1979; Crawford-Volk, 1989; Pascual Chenel / Rodríguez Rebollo, 2015; Andrews, 2016.

${ }^{10}$ Carducho, 1979: XIII.

${ }_{11}$ Carlos Varona, 2013: 203-216.

${ }^{12}$ Crawford-Volk, 1989: 56; Álvarez Lopera, 2005: 91-111.

13 Bustillo, 2016: 164.

${ }^{14}$ Crawford-Volk, 1989: 285-286 y 338-344; Bustillo, 2016: 165.

${ }^{15}$ Nos referimos al último testamento dictado por Vicente Carducho en 1635: Caturla, 1968-1969: 164. 
Tal compromiso seguiría demostrándose con la presencia intermitente del artista en los principales ejercicios auxiliares promovidos por la congregación: las visitas de día, las rondas de noche y la captación de limosnas. La primera labor encomendada al artista se remonta al lunes 12 de marzo de 1629, cuando se le designa el reparto de 150 reales en las visitas de día durante la siguiente semana. ${ }^{16}$ Similar tarea realizará en diciembre de $1634^{17}$ y septiembre de $1637^{18}$ con diferentes cantidades y acompañantes. Asimismo, participó en las rondas de noche - conocidas popularmente como rondas de pan y huevo - ${ }^{19}$ el 26 de julio de $1630^{20}$ y el 16 y 17 de marzo de $1637,{ }^{21}$ repartiendo huevos, panecillos y bizcochos a los menesterosos durante los paseos nocturnos.

Sin duda, el ejercicio reglamentario que desempeñó con mayor reiteración fue el de recaudar limosna por las calles de Madrid. La primera referencia a esta ocupación la encontramos el 15 de marzo de $1630,{ }^{22}$ cuando es elegido para pedir dinero durante el domingo siguiente a las puertas del Refugio. El 6 de abril se tiene cuenta de haber reunido 120 reales en las Carmelitas Descalzas $^{23}$ y el 7 de agosto de 1632 se anotan a su nombre los 16 reales y 30 maravedís que percibió en el Refugio. ${ }^{24}$ Sucesivamente, localizamos varias asignaciones al artista como limosnero el 30 de septiembre de $1633,{ }^{25}$ el 28 de abril de 1634 para servir el día de San Felipe y Santiago ${ }^{26}$ y el 18 de diciembre de 1637 para hacerlo el día de Santo Tomé, ${ }^{27}$ siendo este el último servicio prestado por Carducho en la Hermandad antes de su fallecimiento.

Asimismo, el artista también fue atendido por el Refugio con los beneficios acostumbrados a recibir como hermano. Así se deduce de la visita que se le hizo el 11 de enero de $1630^{28}$ en su domicilio al hallarse enfermo y de otra cita similar el 5 de noviembre de $1638,{ }^{29}$ ya postrado en el lecho de muerte. Lo mismo sucede con los sufragios divinos que la Hermandad dedicó a su alma entre misas, nocturnos, responsos, oraciones, rosarios, salutaciones y salmos desde que se tuvo noticia de su óbito. ${ }^{30}$

Aparte de las ocupaciones benéficas, Carducho no podía obviar que su ingreso iría unido a otras encomiendas altruistas de carácter artístico y que su presencia le permitiría establecer contacto con otros miembros pertenecientes a la élite política e intelectual. De hecho, su aceptación

${ }^{16}$ Las visitas de día consistían en la distribución semanal de limosnas en el domicilio de los pobres enfermos: Ca1lahan, 1980: 108. Ese día Carducho estuvo acompañado del sacerdote Lamberto Conde y del secretario Serra: Libro de Gobierno 3ㅜ, 1625-1629, AHRM, libro-003, 584. Cuentas generales, 1618-1629, AHRM, legajo 150, n. ${ }^{\circ}$ 11, 462. Libro de visitas, AHRM, legajo 330, n. ${ }^{\circ} 1,379-384$.

17 A partir del 22 de diciembre de 1634 se encargó del reparto de 300 reales junto al sacerdote Gabriel Díaz de Robles y Felipe de Moncada: Cuentas generales, 1630-1638, AHRM, legajo 151, n. ${ }^{\circ} 6,094$

18 Durante la semana del 18 de septiembre de 1637 se ocupó de repartir 200 reales junto a Francisco López de Aguilar y Simón Tinoco: Libro de Gobierno 60, 1637-1641, AHRM, libro-006, 102. Cuentas generales, 1630-1638, AHRM, legajo 151, n. $^{\circ} 9,064$.

${ }_{19}$ Corral, 2015: 9-11.

${ }^{20}$ En esta ocasión, el pintor rondó acompañado del licenciado Luis de León y del VII conde de Saldaña: Libro de Gobierno 4 ${ }^{\circ}$, 1629-1634, AHRM, libro-004, 084.

${ }^{21}$ Carducho acudió a la ronda con el licenciado Lope de Morales y Antonio de Robles, quienes socorrieron a dos mujeres enfermas y una muchacha ofreciéndoles dos huevos y medio panecillo a cada una: Libro de Gobierno $6^{\circ}$, 16371641, AHRM, libro-006, 026. Libro de visitas, legajo 296, n. ${ }^{\circ} 8,009$.

${ }^{22}$ Libro de Gobierno 4 ${ }^{\circ}$, 1629-1634, AHRM, libro-004, 041.

${ }^{23}$ También asistieron el licenciado Fernando de Pantoja, Andrés de Prado y Mármol y el secretario Sebastián de Cabezón Hurtado: Cuentas generales, 1630-1638, AHRM, legajo 151, n. ${ }^{\circ} 2,041$.

${ }^{24}$ En esta tarea también participó el licenciado Pablo de los Ríos: Cuentas generales, 1630-1638, AHRM, legajo 151, n. $^{\circ} 4,318$.

${ }^{25}$ El artista fue nombrado junto a Pablo de los Ríos: Libro de Gobierno $4^{\circ}, 1629-1634$, AHRM, libro-004, 443.

${ }^{26}$ Libro de Gobierno 4 $4^{\circ}, 1629-1634$, AHRM, libro-004, 502. Ese día el pintor recaudó un real: Cuentas generales, 1630-1638, AHRM, legajo 151, n. ${ }^{\circ} 6,186$.

27 Libro de Gobierno 6 ${ }^{\circ}$, 1637-1641, AHRM, libro-006, 157.

${ }^{28}$ La Junta envió a Pablo de los Ríos y a Antonio de Robles para ver al pintor: Libro de Gobierno $4^{o}$, 1629-1634, AHRM, libro-004, 022.

${ }_{29}$ Fueron nombrados para visitarle Lope de Morales y Francisco Gracián Berruguete: Libro de Gobierno $6^{\circ}$, 16371641, AHRM, libro-006, 322.

${ }^{30}$ Libro de Gobierno 6 ${ }^{\circ}$, 1637-1641, AHRM, libro-006, 341-342. 
tuvo lugar en un momento crucial en la historia del Refugio, pues unas semanas antes se había inaugurado la nueva iglesia de la Hermandad bajo el nombre de Nuestra Señora de la Concepción ${ }^{31}$ —ubicada en el solar que hoy ocupa la Plaza del Callao- que comenzaría a albergar diferentes obras artísticas adquiridas a través de cuantiosas limosnas y donaciones.

\section{Los miembros de la Hermandad del Refugio en Diálogos de la Pintura}

Las referencias documentales que hemos hallado resultan claves para resolver algunas cuestiones secundarias sobre el ingreso de Carducho en el Refugio. Por ejemplo, en varios de los ejercicios caritativos, el pintor aparece acompañado del licenciado Pablo de los Ríos y Zúñiga, quien consta como uno "de los antiguos hermanos" ${ }^{32}$ Este sacerdote moraba en unas casas colindantes a las del artista, quien llegó a arrendarle "el quarto vaxo" de su propiedad. ${ }^{33}$ Quizás, en esta vecindad podría subyacer algún tipo de amistad o trato concurrido que nos sugiere que el presbítero pudiera haber ofrecido el informe favorable a la Junta para que el artista superase los criterios de selección, tal y como establecían las constituciones de la Hermandad.

Por supuesto, el maestro era consciente de las posibilidades que conllevaría su admisión en cuanto a su promoción personal y familiar, pues así entendemos la sucesiva incorporación de sus sobrinos: el sacerdote José Carducho, que vivía con su tío, el 23 de septiembre de 1633, y el matemático e ingeniero Luis Carducho, residente en casas propias en "la calle del Olmo a espaldas de Antón Martín", el 17 de abril de $1637 .{ }^{34}$ De hecho, José llegó a ocupar el cargo de diputado eclesiástico de juntas particulares en $1637^{35} \mathrm{y}$, al igual que su primo Luis, fue designado regularmente en las tareas semanales. No obstante, parece que la carrera en el Refugio no dio los frutos esperados, pues ambos comienzan a ausentarse abruptamente de los ejercicios tras la muerte de su tío a finales de 1638, siendo solicitados posteriormente para entregar los 5 ducados que el pintor había dejado a la Hermandad en su testamento. ${ }^{36}$

Por otra parte, la presencia del pintor en la congregación también debió de convertirse en un provechoso medio de aproximación hacia el resto de sus miembros. Aunque estas relaciones no constan en la documentación, sí parecen haber sido volcadas de manera implícita por el artista en la redacción de su célebre tratado Diálogos de la pintura, pues es difícil pensar que el maestro no entablara relación con otras personalidades relevantes mencionadas en el texto como el coleccionista Juan de Espina, ${ }^{37}$ el humanista Lorenzo van der Hamen y León ${ }^{38}$ y el doctor Juan Rodríguez de León, ${ }^{39}$ autores de dos pareceres incluidos en la edición impresa.

${ }^{31}$ Corral, 1998: 78.

${ }^{32}$ Aunque firmó el acta de ingreso el 24 de diciembre de 1624, se anota que su aceptación tuvo lugar varios años antes: Libro de Hermanos, 1615-1703, AHRM, legajo 128-1, 145-146. En 1630 ocupó el cargo de tesorero: Libro de Gobierno 4 ${ }^{\circ}$, 1629-1634, AHRM, libro-004, 005.

${ }^{33}$ Testamentaría de Vicente Carducho, 1640, Archivo Histórico de Protocolos de Madrid, (AHPM), Protocolo 5023, fol.152. Caturla, 1968-1969: 158.

${ }^{34}$ Libro de Hermanos, 1615-1703, AHRM, legajo 128-1, 304 y 330.

${ }^{35}$ Libro de Gobierno 5․ 1634-1637, AHRM, libro-005, 313.

${ }^{36}$ Esta cantidad no sería cobrada por la Hermandad hasta el 7 de septiembre de 1640: Libro de Gobierno 6 ${ }^{\circ}$, 1637 1641, AHRM, libro-006, 333 y 609.

${ }^{37}$ Aunque Juan de Espina no llegó a ser miembro de la Hermandad, se le considera benefactor al haber donado cien cuadros de pintura en 1626 para la iglesia del Refugio, los cuales pudo haber visto Carducho. Lista de bienhechores, siglo XIX, AHRM, legajo 373, n. ${ }^{\circ}$ 2, 005. De hecho, el pintor conoció a Espina antes de ingresar en la Hermandad, tal y como demuestra la visita que realizó el 10 de abril de 1628 a la colección de manuscritos, obras de arte y curiosidades que custodiaba en su casa: Reula Baquero, 2019: 102.

${ }^{38}$ Lorenzo van der Hamen y León (1589-1664), capellán del convento del Corpus Christi, ingresó como hermano el 26 de agosto de 1632, inmediatamente antes que José Carducho: Libro de Hermanos, 1615-1703, AHRM, legajo 128-1, 304. En 1634 ocupó el cargo de maestro de ceremonias: Libro de Gobierno 4 ${ }^{\circ}$, 1629-1634, AHRM, libro-004, 463. En 1635 fue diputado eclesiástico para las juntas generales: Libro de Gobierno 5º 1634-1637, AHRM, libro-005, 063.

${ }^{39}$ Este ingresó el 18 de abril de 1628: Libro de Hermanos, 1615-1703, AHRM, legajo 128-1, 238. 
Lo mismo podría ocurrir con los aristócratas elogiados en el libro como "señores que favorecen la pintura", ${ }^{40}$ tales como el príncipe de Esquilache ${ }^{41}$, el VIII conde de Lemos, ${ }^{42}$ el II duque de Medina de las Torres, ${ }^{43}$ el IX conde de Benavente ${ }^{44}$ o el caballerizo de la reina Francisco Velázquez Minaya ${ }^{45}$ todos ellos miembros antes de 1628. Carducho subraya elocuentemente las inclinaciones culturales de estos aficionados y diletantes haciendo referencia a la decoración de sus residencias y colecciones, resultando particularmente interesantes las observaciones acerca del caballero Minaya, quien llegó a iniciarse en la práctica pictórica ${ }^{46} \mathrm{y}$ cuyos conocimientos artísticos debieron de ser de gran utilidad para la Hermandad, razón por la que se le encargó seguramente la resolución de las gestiones artísticas como miembro de la comisión de obras para la construcción de la nueva iglesia del Refugio desde $1626 .{ }^{47}$

Es cierto que la confluencia de estos personajes en la congregación no impide que Carducho los hubiese conocido antes de su ingreso, algo que es totalmente factible dada su frecuente presencia en el entorno cortesano. Sin embargo, creemos que no ocurre lo mismo en el caso de los Enríquez de Ribera, pues los testimonios vertidos en el tratado evidencian algún tipo de encuentro o entrevista personal a través de la Hermandad y cuyo desarrollo podemos intuir. Dentro del mencionado grupo de aristócratas, el artista dedica unas palabras a Pedro Girón Enríquez de Ribera (1586-1633), II marqués de Alcalá de la Alameda. Este noble de origen sevillano, cuya biografía no ha trascendido, ostentó dicho título en calidad de consorte a través de su matrimonio con Antonia Portocarrero y Cárdenas, de la que enviudó en 1613. Al desposar a su única hija con el VII duque de Medinaceli en 1625, se trasladó a Madrid, donde residió hasta su muerte.

A pesar de su discreta trayectoria, fue aceptado como hermano del Refugio el 30 de octubre de $1626^{48}$ y pronto comenzó a ascender en los oficios de la congregación hasta ocupar el cargo de Hermano Mayor desde finales de 1629 hasta finales del mes de junio de 1633. En sus Diálogos, el pintor florentino lo ensalza como "honor de la virtud y las ciencias" que estimó y alabó la pintura, ${ }^{49}$ aunque desconocemos si el artista llegó a visitar la escueta colección pictórica que este noble poseyó en unas casas de la calle del Almendro, entre cuyos ejemplares tan solo destaca un lienzo de la Coronación de la Virgen de Blas de Prado y un Cristo en la columna de Luis de Morales "el de Badajoz" ${ }^{50}$ Sin embargo, las referencias en su tratado parecen describir más la cultivada personalidad del marqués que la posesión de un portentoso repertorio pictórico, pues estas opiniones debieron de fraguarse a consecuencia del contacto de ambos en el Refugio, donde coincidirían en más de una ocasión durante la celebración de las juntas.

Tuvo que ser a través del marqués cómo el pintor conocería a su joven yerno Antonio Juan Luis de la Cerda (1607-1671), VII duque de Medinaceli y miembro del Refugio desde $1628,{ }^{51}$ al que

40 Carducho, 1979: 443.

${ }^{41}$ Francisco de Borja y Aragón (1582-1658), príncipe de Esquilache y I conde de Mayalde, ingresó el 10 de abril de 1627 y ostentó el cargo de Hermano Mayor en 1635: Libro de Hermanos, 1615-1703, AHRM, legajo 128-1, 218.

${ }_{42}$ Francisco Ruiz de Castro (1579-1637), VIII conde de Lemos, ingresó el 18 de diciembre de 1626 y fue consiliario seglar en 1628: Libro de Hermanos, 1615-1703, AHRM, legajo 128-1, 208.

${ }^{43}$ Ramiro Núñez de Guzmán (†1668), II marqués de Medina de las Torres, fue aceptado el 17 de diciembre de 1627 y ocupó el cargo de enfermero en 1631: Libro de Hermanos, 1615-1703, AHRM, legajo 128-1, 232.

${ }_{44}^{44}$ Antonio Alonso de Pimentel (†1633), IX conde y VI duque de Benavente y VII conde de Luna, ingresó el 20 de agosto de 1621: Libro de Hermanos, 1615-1703, AHRM, legajo 128-1, 142.

${ }_{45}$ Francisco Velázquez Minaya (†1656), caballero de la orden de Santiago, ingresó el 10 de abril de 1623 y ocupó el puesto de mayordomo en 1633: Libro de Hermanos, 1615-1703, AHRM, legajo 128-1, 156

${ }^{46}$ Burke / Cherry, 1997: 37.

${ }^{47}$ Libro de Gobierno 3º 1625-1629, AHRM, libro-003, 178.

48 Libro de Hermanos, 1615-1703, AHRM, legajo 128-1, 205.

${ }^{49}$ Carducho, 1979: 444.

${ }^{50}$ Pérez Preciado, 2016: 142 y 146, n. ${ }^{\circ}$ 19. De la larga lista de enseres que el marqués dejó tras su muerte, observamos que las pinturas quedan en un plano muy secundario en comparación con el rico conjunto de tapices de temática mitológica, la valiosa selección de relojes autómatas y musicales, y la biblioteca compuesta por más de 1.600 libros: Inventario, tasación y almoneda de bienes de Pedro Girón de Ribera, II marqués de Alcalá de la Alameda, 7 de julio de 1633, AHPM, Protocolo 2.689, fols. 704-875v.

${ }^{51}$ Este ingresó el 25 de febrero de 1628 y moraba frente a los Carmelitas Descalzos: Libro de Hermanos, 1615-1703, AHRM, legajo 128-1, 234. 
identifica erróneamente como "su dignísimo hermano" y al que alaba por "amparar estas facultades del dibujo", ${ }^{52}$ haciendo referencia seguramente a una desconocida colección de diseños. Sin embargo, el personaje que mayor espacio ocupa en este fragmento es Fernando Afán Enríquez de Ribera (1583-1637), III duque de Alcalá de los Gazules, hermano mayor del marqués y miembro de la Hermandad desde el 27 de agosto de $1626 . .^{53}$

Carducho menciona al aristócrata en dos ocasiones, además de añadir otra cita contenida en un escrito anexo compuesto por José de Valdivielso. En la primera ocasión, lo incluye en el diálogo imaginario tenido entre un maestro pintor y su discípulo, en el que ambos discuten sobre la reacción del rey Felipe III ante el fatídico incendio del Palacio del Pardo acaecido en $1604 .{ }^{54} \mathrm{Al}$ parecer, el monarca mostró cierto alivio al saber del salvamento del Júpiter y Antíope de Tiziano frente al resto de cuadros de la colección real que sucumbieron a las llamas, actitud que es parangonada en la fingida conversación con una anécdota similar supuestamente narrada por el III duque de Alcalá en Italia:

Parécese esto a lo q[ue] oí contar al duque de Alcalá en Nápoles, q[ue] avié[n]dosele quemado a un caballero la casa, y no pudie[n]do salvar todo lo q[ue] en ella avía, asió de una pintura q[ue] estimava mucho y abraçado co[n] ella, salió a la calle y viéndose libre con su pintura, dixo: ¡Ahora más, que se queme todo! ${ }^{55}$

Aunque desconocemos mayores detalles sobre este suceso, ${ }^{56}$ es muy probable que Carducho se hiciese eco de esta historia a través del propio duque, que residió en Madrid desde octubre de 1631 hasta, al menos, mediados de marzo de 1632, después de haber sido destituido del cargo de virrey de Nápoles. No obstante, la certeza sobre este encuentro se desprende de una segunda cita contenida en los Diálogos:

[...] y el duque de Alcalá conocido en estos siglos por sus clarísimos títulos, y en Italia, por la eminencia de su govierno en el principado de Cataluña, reinos de Nápoles y Sicilia, y en particular el ho[n]rador de nuestros professores por singulares modos, procurando q[ue] el adorno de su casa sean valientes pinturas antiguas y modernas, haziéndola un magnífico museo de las más preciosas que se han hecho en el mundo a costa de particular cuidado y gran tesoro de sus muchas rentas, añadiendo con este virtuoso afecto una piedra brillante a la gloria de su ilustrísima casa. ${ }^{57}$

El análisis de este fragmento nos ofrece importante información sobre la relación de ambos personajes y el propio proceso de redacción del tratado. En primer lugar, el pintor menciona algunos de los cargos gubernamentales ostentados por Alcalá a lo largo de su carrera diplomática, siendo especialmente reveladora su condición de virrey de Sicilia. Este nombramiento se produjo el 7 de marzo de 1632 en Madrid, ${ }^{58}$ lo que evidencia que este fragmento del Diálogo VIII fue escrito entre esa fecha y el 30 de agosto de aquel año, cuando el manuscrito ya había sido entregado para su aprobación, ${ }^{59}$ siendo seguramente una de las últimas partes del libro en ser redactadas.

En segundo lugar, Carducho elogia la colección pictórica que el III duque de Alcalá concentró en su residencia sevillana: la Casa de Pilatos. Es curioso que el pintor haga una descripción tan verosímil de un lugar en el que nunca estuvo, lo que nos lleva a pensar que conocía estos datos por tradición oral, ya que no consta que viajase jamás a Sevilla. Por otro lado, es importante tener

52 Carducho, 1979: 444.

53 Libro de Hermanos, 1615-1703, AHRM, legajo 128-1, 202.

${ }^{54}$ Carducho, 1979: 436.

55 Carducho, 1979: 436.

${ }^{56}$ Quizás podría tratarse del incendio ocurrido el 14 de enero de 1631 en el Palacio de Guido Ubaldo Trionfi en Ancona (Le Marche), en el que ardieron buena parte de sus bienes y perecieron varios criados. Aquella noche pernoctaba en el palacio la infanta María de Austria, futura reina de Hungría: Parrino (1692): 209.

57 Carducho, 1979: 443-444.

${ }^{58}$ Gascón de Torquemada, 1991: 334.

${ }^{59}$ Carducho, 1979: 5. 
en cuenta que, en agosto de 1631, se encontraba provisionalmente en Madrid una remesa de veinticuatro cajones que contenían las obras artísticas adquiridas durante la estancia de Alcalá como virrey de Nápoles entre 1629 y 1631 y que esperaban ser enviadas rumbo a Sevilla. ${ }^{60}$

Nos parece arriesgado proponer que el artista florentino llegase a ver las piezas embaladas en las gavetas, pero sí resulta viable que tuviese noticias sobre la colección ducal en un probable encuentro personal con el III duque de Alcalá, en el que debió de quedar maravillado sobre la pretensión del aristócrata por recoger un "magnífico museo" en su palacio, abasteciéndose de importantes modelos pictóricos antiguos y modernos. Las piezas encajonadas sí serían contempladas por el pintor Francisco Pacheco meses después en Sevilla, sirviéndole de apoyo en varios de los juicios emitidos en su tratado Arte de la Pintura. ${ }^{61}$ El maestro andaluz debió de quedar desilusionado al saber que Carducho se le había adelantado en la publicación de un texto de naturaleza similar ${ }^{62}$ en el que, además, bebía de algunas de las fuentes que creería exclusivas e inéditas, ${ }^{63}$ cuestión que debió de alimentar la supuesta rivalidad entre ambos artistas.

Aunque resulta factible que Carducho y Alcalá ya se conociesen con anterioridad dados los continuos viajes del duque a Madrid, la presencia de los Enríquez de Ribera en la congregación tuvo que ser un factor decisivo en su interacción con el pintor y en las declaraciones vertidas en el tratado, en las que también influyeron algunas de las gestiones artísticas encomendadas al maestro. La presencia de un San Jerónimo penitente atribuido a uno de los hermanos Carducho en la colección ducal,${ }^{64}$ no hace sino ratificar la relación entre ambos reflejada en los Diálogos de la pintura.

\section{Vicente Carducho y el retablo para el altar mayor de la iglesia del Refugio}

Precisamente, la noticia que nos ha puesto sobre la pista de la presencia de Carducho en la Hermandad es una misiva escrita desde Nápoles por el III duque de Alcalá a su hermano menor, II marqués de Alcalá, el 30 de marzo de $1631 .{ }^{65}$ Ambos nobles — miembros del Refugio desde 1626 - procedían de un poderoso linaje andaluz con un papel esencial en la promoción artística y el coleccionismo en Sevilla, ${ }^{66}$ si bien por aquellos años habían intensificado su presencia en la corte ampliando sus lazos familiares y obteniendo distintas mercedes reales.

Dicha carta anuncia la inminente culminación de una pintura "que ha de dar mucha satisfaçión", destinada a presidir el altar mayor de la iglesia del Refugio junto a unos ornamentos, y para cuya ejecución se habían recibido unas medidas que no se especifican. ${ }^{67}$ Casi cuatro meses más tarde, el

${ }^{60}$ Registro de cartas politicas, siglo XVII, Biblioteca Nacional de España (BNE), Mss/9882, 232 y 289.

${ }^{61}$ Pacheco, 1990: 113.

${ }^{62}$ Desde luego, Pacheco debió de permanecer ajeno a la preparación de los Diálogos, pues en el capítulo VII del Arte de la Pintura, redactado en 1632, se refiere al pintor florentino como "nuestro íntimo amigo": Pacheco, 1990: 191.

${ }_{63}$ Por ejemplo, Carducho ofrece algunos datos sobre el hallazgo de las Bodas Aldobrandini en Roma en 1606, fragmento de una pintura al fresco que fue conocida y descrita por Pacheco en el Arte de la Pintura a través de una copia en lienzo llevada a Sevilla por el III duque de Alcalá en 1626. No obstante, es muy probable que Carducho supiese de la existencia de la pieza años antes a través de las noticias ofrecidas por el pintor Federico Zuccaro: Carducho, 1979: 251; Pacheco, 1990: 114. En los Diálogos también se incluye un texto de José de Valdivielso en el que se menciona al pintor Diego de Rómulo, artista que acompañó al duque hasta Roma y fue condecorado por Urbano VIII con el título de Caballero de la Orden de Cristo y una cadena de oro. Pacheco demuestra en su tratado que conoció de una manera más amplia y precisa todas estas noticias gracias a Alcalá, por lo que entendemos el malestar que le provocó saber que su colega las hubiese publicado primero.

64 "IV.14. Un Sanct Gerónimo del Carducho con g ${ }^{\text {on }}$ dorada dándosse con una piedra en los pechos mirando un Xpo": Brown / Kagan, 1987: 250. Respondiendo a esa descripción, un san Jerónimo (113 x $89 \mathrm{~cm})$ atribuido a Vicente Carducho se subastó en Sevilla el 18-12-2019 en Isbilya. Subasta de arte, lote n. $^{\circ} 76$.

${ }^{65}$ Registro de cartas políticas, siglo XVII, BNE, Mss/9882, $128 \mathrm{v}$.

${ }_{66}^{6}$ Para la colección sevillana del III duque de Alcalá, véase: Brown / Kagan, 1987; Lleó Cañal, 2017.

${ }^{67}$ Respecto a las medidas de la pintura, el duque escribe: "No me atrebí a deziros que, con las mudanças, el tiempo questubo aquí la reyna se me havían perdido las medidas que de aí se me embiaron, que me truxeron loco hasta q[ue] las allé”: Registro de cartas políticas, siglo XVII, BNE, Mss/9882, 128v. 
26 de julio, estando el duque retenido en Guadalajara, pide a su secretario Juan Antonio de Herrera que diese "mucha priesa al caballero Máximo para que acabe el lienço que pinta para el Refuxio" y le manda hacer "una buena cornisa dorada de las estrabagantes q[ue] hazen en Náp[ole]s [...] de man[er]a que se pueda desbaratar para que benga en algún caxón y se harme acá" ${ }^{68}$

La llegada del cuadro con su marco a Madrid debió de producirse antes del 16 de septiembre de $1633,{ }^{69}$ cuando la Junta acuerda tratar con el arquitecto Juan Gómez de Mora y el pintor Vicente Carducho para que "viesen el mejor modo q[ue] puede aber para q[ue] se ajuste el retablo q[ue] el s[eño]r duq[ue] de Alcalá envió de limosna a la Her[man]dad, poniendo una grada entre él y el altar y el remate que se debe haçer". ${ }^{70}$ Estas últimas modificaciones se deben a que Carlos de Borja y Aragón, VII duque de Villahermosa, ${ }^{71}$ había decidido ampliar la obra financiando la hechura de un remate cuyo diseño correría a cargo del florentino. Por esta razón, en la Junta del 24 de mayo de 1634 se anota:

Viéronse unos dibuxos para una obra que el s[eño]r duque de Villahermosa quiere hazer sobre el retablo de la yglessia, que traxo hechos Vicençio Carducho. Y se le bolvieron señalando uno que pareçía más a propóssito para que comunique con un escultor en quánto hará la obra dorada y todo, y con su pareçer le remita la resoluçión dello a la Hermandad. ${ }^{72}$

Aunque la documentación omite cualquier tipo de referencia iconográfica o decorativa sobre la obra, nos inclinamos a relacionar los diseños citados con un par de bocetos atribuidos al artista conservados en la Biblioteca Nacional de España, que representan sendos Ángeles con tarjas y una lanza [figs. 2 y 3] en diferentes posturas y que se identifican como dos propuestas realizadas para la traza de un ático de un desconocido retablo en el que intervendrían Gómez de Mora y Carducho. ${ }^{73}$ En nuestra opinión, tanto el escudo en el que se apoyan las figuras como las diferentes manos que pudieron ejecutar la parte arquitectónica y la parte escultórica de los bosquejos parecen encajar con la empresa artística patrocinada por el Refugio, donde colaboraron ambos artistas.

No volvemos a encontrar noticias acerca del remate hasta los primeros meses de 1636, cuando localizamos varias referencias muy someras sobre las entrevistas tenidas con el maestro pintor para tratar sobre el avance de su ejecución. ${ }^{74}$ A partir del 4 de abril, Fernando Fernández de Cardona y Córdoba realiza una manda de 200 reales para animar al resto de miembros a secundarle con otras consignaciones y sufragar los gastos de "hazer lo que falta al retablo" —alcanzándose la cifra de 542 reales ese día - además "de la pintura q[ue] fuesse necesaria, q[ue] esta la ofreció de limosna el s[eño]r Vicencio Carducho" ${ }^{75}$ Respecto a esta donación, solo podemos suponer que consistiese en un pequeño cuadro para el ático del retablo, tal vez con un asunto complementario y amable como la Coronación, Dios Padre bendiciendo o la Anunciación.

Reconstruyendo el encargo comisionado por Alcalá, parece obvio que el caballero que ultimaba la pintura en 1631 para presidir el retablo era el pintor Massimo Stanzione (1585-1656), ${ }^{76}$ exponente del naturalismo pictórico napolitano junto a José de Ribera. Sin embargo, hemos sido incapaces de seguir el rastro a este cuadro en la documentación, ${ }^{77}$ aunque damos por hecho que en

${ }^{68}$ Registro de cartas políticas, siglo XVII, BNE, Mss/9883, 213v.

${ }^{69}$ El 20 de enero de 1634, el III duque de Alcalá mandó restituir los 100 ducados que adelantó el Refugio por los fletes de los cajones del retablo. Dicha cantidad se cobró el 10 de febrero: Libro de Gobierno $4^{\circ}$, 1629-1634, AHRM, libro-004, 476 y 482.

70 Libro de Gobierno 4', 1629-1634, AHRM, libro-004, 440.

${ }^{71}$ Callahan, 1980: 179.

72 Libro de Gobierno 4 ${ }^{\circ}$, 1629-1634, AHRM, libro-004, 517.

${ }^{73}$ Las dimensiones de los dibujos son 14 x $11 \mathrm{~cm}$ y 10 x 10,5 cm, respectivamente: Pascual Chenel / Rodríguez Rebollo, 2015: 248-250. Los autores no lo asocian a la obra del Refugio.

${ }^{74}$ Concretamente, el 25 de enero, el 18 de febrero y el 11 de marzo de 1636: Libro de Gobierno 5o, 1634-1637, AHRM, libro-005, 216, 224 y 229.

${ }^{75}$ Libro de Gobierno 5 $5^{\circ}$ 1634-1637, AHRM, libro-005, 233.

${ }^{76}$ En cuanto a la vida y obra de este pintor y caballero, véase: Schütze / Willette, 1992.

${ }^{77}$ Las características de la pintura realizada para el Refugio no parecen coincidir con ninguno de los ejemplares 

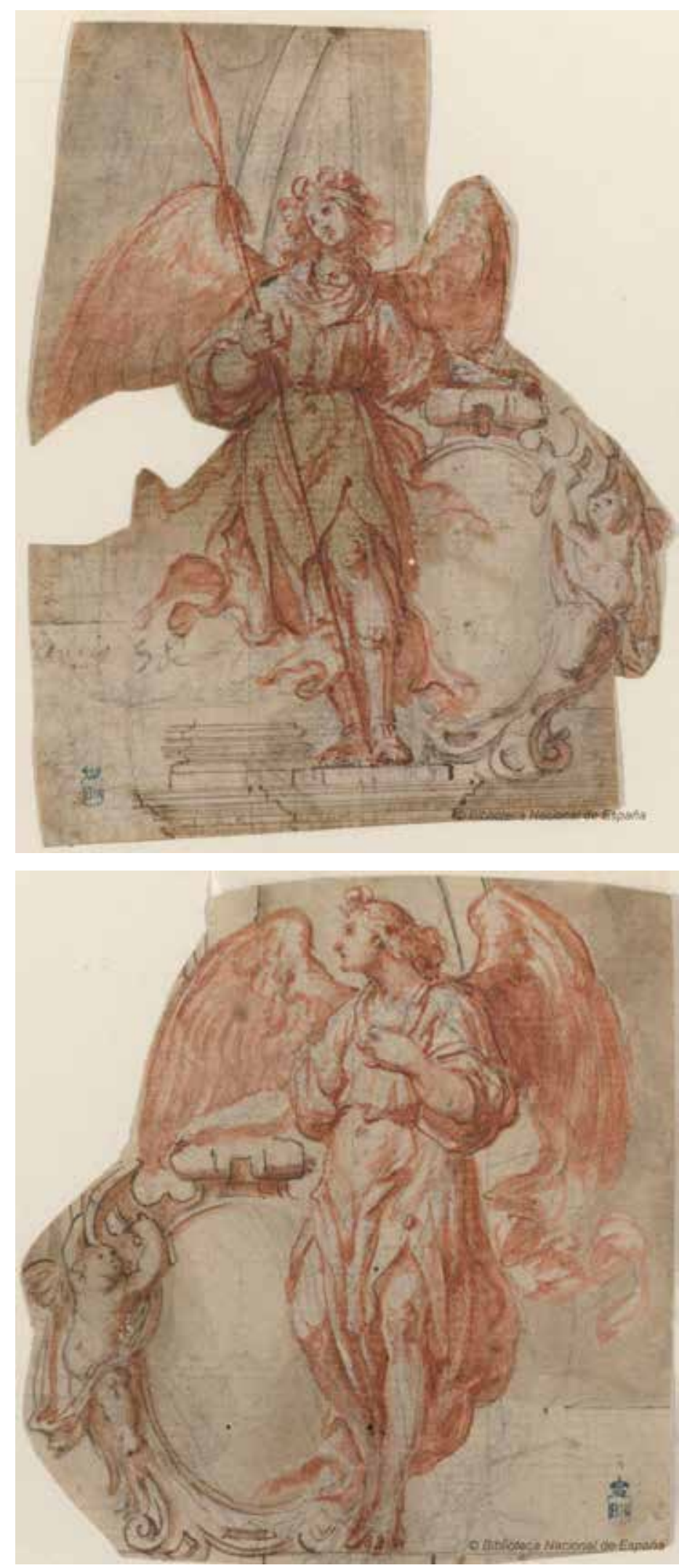

Fig. 2. Vicente Carducho, Ángel con lanza y tarja, h.1633. Madrid: Biblioteca Nacional de España (Fot. BNE).
Fig. 3. Vicente Carducho, Angel con tarja, h.1633. Madrid: Biblioteca Nacional de España (Fot. BNE).

Archivo Español de Arte, vol. XCIV, n. ${ }^{\circ} 375$, pp. 233-246, julio-septiembre 2021 ISSN: 0004-0428, eISSN: 1988-8511, https://doi.org/10.3989/aearte.2021.14 
él se representaba a la Inmaculada Concepción, advocación mariana a la que se adscribía la nueva iglesia del Refugio.

No olvidemos que la principal función de la Hermandad era la beneficencia y que, ante la continua necesidad de obtener ingresos en metálico, era habitual que muchas de sus obras de arte acabasen siendo liquidadas. Así, Carducho también sería requerido para ocuparse de este tipo de gestiones, tasando pinturas y poniéndolas a la venta. Justamente, el 25 de agosto de 1634, la Junta le remite un mensaje para que apreciase unos cuadros entre los cuales había una imagen que había regalado el III duque de Alcalá que se encontraba en poder del secretario Sebastián de Cabezón Hurtado, ${ }^{78}$ y el viernes siguiente se ordena al hermano Juan Jacinto de Velasco que pusiese a la venta un Ecce Homo procedente de "uno de los colaterales" de la iglesia junto a otras dos pinturas que había tasado el maestro. ${ }^{79}$

Es poco probable que entre ellas se encontrase la obra de Stanzione, sino "una pintura grande de N[uest]ra S[eño]ra de la Misericordia" donada por Alcalá el 14 de mayo de 1627 "para que se ponga en la yglesia" ${ }^{\$ 0}$ que aún estaba en construcción, por lo que fue posteriormente depositada en casa del sacristán Pedro del Castillo. Parece que esta pintura nunca llegó a ocupar su destino, pues en noviembre de 1628 se decide que — para la misa de la consagración del nuevo templo— ${ }^{81}$ el altar mayor estuviese presidido por una imagen de la Inmaculada Concepción, motivo por el que el secretario Hurtado se ofreció a prestar provisionalmente un cuadro con este mismo asunto, mientras que, a cambio, se llevaría el cuadro que había donado el duque ${ }^{82}$ Casi seis años después, la Junta ordenó al secretario que entregase la pieza para subastarla por "no haber ya donde ponerla", enviando el citado mensaje a Carducho para proceder a su tasación. ${ }^{83}$

La obra peritada por el artista debía de ser la misma que fue vendida entre el 14 y el 20 de octubre de 1634, cuya salida consta como "ciento y beinte reales del preçio de la echura de una ymagen de $\mathrm{N}$ [uest]ra S[eñor]a con dos pobres de rodillas a los pies, que se ferió por orden del $\mathrm{s}$ [eño]r Juan Jaçinto de Belasco. $120 \mathrm{r}$ [eale]s" ${ }^{84}$ De este modo, el modelo del cuadro no podía ser otro que el de la Virgen de Loreto o de los Peregrinos de Caravaggio, del que existe una copia en el Museo Lázaro Galdiano de Madrid [fig. 4]. ${ }^{85}$ La pintura fue seguramente copiada a través de otra reproducción idéntica importada por Alcalá desde Roma tras ocupar el cargo de embajador de obediencia entre 1625 y $1626,{ }^{86}$ lo que nos permite localizar por estas fechas la presencia de, al menos, tres copias de este mismo asunto entre Sevilla y Madrid. ${ }^{87}$

Por lo que respecta a la hechura del remate, desconocemos si existió algún tipo de documento contractual, aunque la Junta comienza a ordenar una serie de pagos fraccionados a un escultor anónimo entre 1636 y $1637 .{ }^{88}$ Es difícil colegir el precio total al que ascendió la obra, pero la suma de

comprendidos en el catálogo de Stanzione. La única obra del artista de temática similar es una Inmaculada Concepción encargada en 1643 por el abogado italiano Lorito Giuseppe Pitasi para un altar lateral de la Chiesa di Gesú e Maria di Costantinopoli en Pescocostanzo (L'Aquila): Signorini, 2014: 457.

${ }_{78}$ Libro de Gobierno 5 ${ }^{\circ}$, 1634-1637, AHRM, libro-005, 025.

79 Libro de Gobierno 5 ${ }^{\circ}$, 1634-1637, AHRM, libro-005, 026.

${ }^{80}$ Libro de Gobierno $3^{\circ}$. 1625-1629, AHRM, libro-003, 280.

81 Esta ceremonia tuvo lugar el 12 de diciembre de 1628: Libro de Gobierno 3‥ 1625-1629, AHRM, libro-003, 531.

82 "Tratose cómo era necess[ari]o poner en el altar mayor una ymagen de N[uest]ra S[eñor]a de la Conçepción. Ofreció el s[ecretari]o de esta Her[man]dad de prestar una que tiene en el ynter que se haze, de tres baras menos sesma de largo y dos y sesma de ancho. Y la Hermandad mandó que llevase a su casa la ymagen q[ue] está en poder del lic[encia] do P[edr]o del Castillo que dio el s[eño]r duque de Alcalá: Libro de Gobierno 3‥ 1625-1629, AHRM, libro-003, 517. Según estos datos, la pintura que prestó el secretario temporalmente hasta que llegara la obra de Stanzione, mediría unos 2'36 x 1'81 metros aproximadamente.

${ }^{83}$ Libro de Gobierno 5 ${ }^{\circ}$, 1634-1637, AHRM, libro-005, 023.

${ }^{84}$ Cuentas generales, 1630-1638, AHRM, legajo 151, n. ${ }^{\circ}$ 6, 303.

${ }^{85}$ El lienzo mide 2'34 x 1'48 m.

86 Brown / Kagan, 1987: 235.

${ }^{87}$ En concreto, la del oratorio del III duque de Alcalá en la Casa de Pilatos desde 1626, la de la colección de Vittoria Colonna inventariada en marzo de 1634 que pasa al IX almirante de Castilla y la vendida por el Refugio en octubre de 1634. Véase: Brown / Kagan, 1987: 241; Burke /Cherry, 1997: 299 y 432; Cruz Yábar, 2017: 547-548.

${ }^{88}$ Libro de Gobierno 5º 1634-1637, AHRM, libro-005, 241, 273, 297, 307 y 309; Libro de Gobierno 6 ${ }^{o}$, 1637-1641, AHRM, libro-006, 012. 


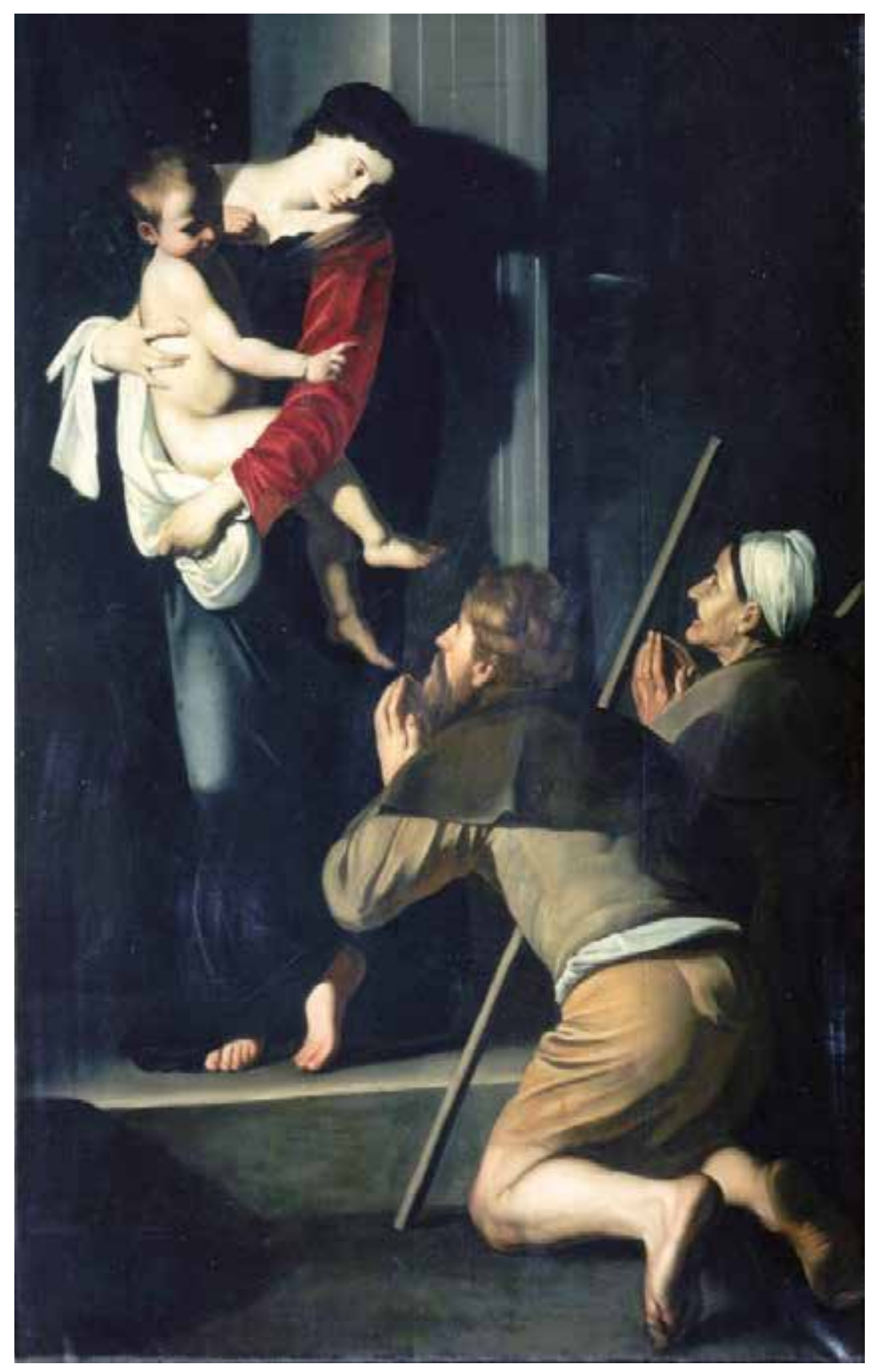

Fig. 4. Copia del original de Caravaggio, La Virgen de Loreto o de los Peregrinos, siglo XVII. Madrid: Museo Lázaro Galdiano (Fot. MLG).

los desembolsos debió de superar con creces los 1.860 reales. Gracias a una carta de pago fechada el 8 de febrero de $1637^{89}$ sabemos que el destinatario de estas entregas era Juan de Echalar, quien se comprometió a la hechura, grabado, dorado y estofado del remate del retablo.

Lamentablemente, no conocemos demasiados datos sobre este maestro arquitecto, escultor y ensamblador en activo desde $1611,{ }^{90}$ aunque en cuanto a su relación con la Hermandad resulta

${ }^{89}$ Cuentas generales, 1630-1638, AHRM, legajo 151, n. ${ }^{\circ}$ 9, 014.

${ }_{90}$ El autor, también llamado Juanes de Echalar o Juan de Chalar, aparece referido en otros documentos con estos tres oficios: Agulló y Cobo, 1978: 59-61, 112. 
sugestivo que poseyese unas casas en la calle de Jacometrezo, muy cerca del emplazamiento de la nueva sede e iglesia. También es interesante su participación junto a Gómez de Mora en la ejecución del retablo de San Juan de Dios del Hospital de Antón Martín en 1633, cuyas pinturas pudieron haber sido inicialmente encargadas a Carducho. ${ }^{91}$ Este trinomio coincidiría paralelamente en la obra del retablo del Refugio, si bien, nuestro descubrimiento compone la única prueba documental que nos permite constatar la participación del pintor en el diseño de un retablo, aunque de manera parcial.

\section{Conclusiones}

La membresía de Vicente Carducho en la Hermandad del Refugio originó un tipo de colaboración en la que maestro y congregación saldrían beneficiados. De esta manera, la Junta contó con la utilidad de un pintor experimentado, culto e influyente que se hizo cargo de las peticiones artísticas, mientras que el florentino aprovechó las posibilidades de aumentar su prestigio social y el de sus sobrinos entrando en contacto con un distinguido círculo de coleccionistas, aficionados y diletantes pertenecientes a la élite aristocrática y al sector eclesiástico y cortesano. Además, el entorno en el que se daban estos encuentros semanales permitiría un trato mucho más fluido y directo - muy diferente al que imponía la etiqueta y el protocolo en la corte - que contribuiría a crear el ambiente idóneo en el que aproximarse a sus inclinaciones artísticas, las cuales acabaría reflejando en su tratado Diálogos de la Pintura.

Finalmente, queda claro que nuestras pesquisas dejan aún abiertas muchas cuestiones que merecen de una mayor atención, si bien, complementan nuestro conocimiento sobre el próspero periodo profesional del que gozó el artista durante su última década de vida, etapa en la cual afrontaría una mayor demanda de encargos por parte de diferentes congregaciones religiosas y cenobios madrileños. Estas noticias contribuyen a ampliar la información sobre las interesantes obras artísticas que poseyó la Hermandad, donadas o patrocinadas por sus miembros, y, especialmente, sobre las circunstancias en las que se realizaron o llegaron a formar parte de su acervo cultural, aún muy poco estudiado.

\section{BIBLIOGRAFÍA}

Agulló y Cobo, Mercedes (1978): Documentos sobre escultores, entalladores y ensambladores de los siglos XVI al XVIII. Valladolid: Publicaciones del Departamento de Historia del Arte.

Álvarez Lopera, José (2005): "La reconstrucción del Salón de Reinos. Estado y replanteamiento de la cuestión". En: Úbeda de los Cobos, Andrés (ed.): El Palacio del Rey Planeta: Felipe IV y el Buen Retiro. Madrid: Museo Nacional del Prado, pp. 91-111.

Andrews, Jean / Noble Wood, Oliver / Roe, Jeremy (2016): On Art and Painting: Vicente Carducho and Baroque Spain. University of Wales Press.

Angulo Íñiguez, Diego (1966): Cuarenta dibujos españoles. Dibujos de la Real Academia de San Fernando. Madrid.

Arranz Otero, José Luis / Gutiérrez Pastor, Ismael (1999): "La decoración de San Antonio de los Portugueses de Madrid (1660-1702)". En: Anuario del Departamento de Historia y Teoría del Arte, 11, pp. 211-250.

Brown, Jonathan / Kagan, Richard (1987): "The Duke of Alcalá: His Collection and Its Evolution”. En: Art Bulletin, 69, 2, pp. 231-255.

Burke, Marcus B. / Cherry, Peter (1997): Collections of Paintings in Madrid. 1601-1755. Los Angeles: The Provenance Index of Getty Information Institute.

${ }_{91}$ Los dos dibujos de los Ángeles con tarjas también se asocian a un proyecto para el remate del retablo de San Juan de Dios del Hospital de Antón Martín en 1633, cuyas pinturas se piensa que fueron realizadas por el artista granadino Alonso Cano a partir de 1638: Pascual Chenel / Rodríguez Rebollo, 2015: 246. Responsables de la ejecución de este retablo, entre julio de 1633 y febrero de 1635, fueron: Gómez de Mora como tracista, Juan de Echalar como ensamblador y Juan Sánchez Barba como escultor del Crucificado en el remate. Cruz Yábar defiende que las pinturas no serían de Alonso Cano y sí podrían haberse encargado —al menos las dos inferiores_ a Vicente Carducho: Cruz Yábar, 2019: 566-567. 
Bustillo, Marta (2016): "Carducho and Ideas about Religious Art”. En: Andrews, Jean / Noble Wood, Oliver / Roe, Jeremy (eds.): On Art and Painting: Vicente Carducho and Baroque Spain. University of Wales Press, pp. 163-181.

Callahan, William J. (1980): La Santa y Real Hermandad del Refugio y Piedad de Madrid (1618-1832). Madrid: Instituto de Estudios Madrileños.

Carducho, Vicente (1979): Diálogos de la pintura: su defensa, origen, esencia, definición, modos y diferencias [1633]. Calvo Serraller, Francisco (ed.). Madrid: Turner.

Carlos Varona, María Cruz de (2013): "Vicente Carducho en el El Paular y la elaboración de un imaginario cartujano". En: Barceló de Torres, Eduardo / Ruiz Gómez, Leticia (eds.): La recuperación de El Paular. Madrid: Ministerio de Educación, Cultura y Deporte.

Caturla, María Luisa (1968-1969): "Documentos en torno a Vicente Carducho". En: Arte español. Revista de la Sociedad Española de Amigos del Arte, XXVI, pp. 145-221.

Corral, José del (1998): El Padre Bernardino de Antequera, los fundadores de la Hermandad del Refugio y Piedad de esta corte y el Madrid de su época. Madrid: Hermandad del Refugio.

Corral, José del (2015): “Cuatrocientos años ayudando a los necesitados”. En: Gómez Laínez, Mariola (2015): Santa, Pontificia y Real Hermandad del Refugio y Piedad de Madrid: la iglesia de San Antonio de los Alemanes: IV centenario. Madrid: Santa, Pontificia y Real Hermandad del Refugio y Piedad, pp. 9-89.

Cossío y Gómez-Acebo, Manuel (1915): La Santa, Pontificia y Real Hermandad del Refugio y Piedad de Madrid. Madrid: Imprenta del Asilo de Huérfanos.

Crawford-Volk, Mary (1989): Vicencio Carducho and Seventeenth-Century Castilian Painting. U.M.I., Dissertation Information Service.

Cruz Yábar, Juan María (2017): "Contribuciones a las pinturas del IX Almirante de Castilla”. Anales del Instituto. de Estudios Madrileños, 57, pp. 527-558.

Cruz Yábar, Juan María (2019): “Alonso Cano, escultor en la Corte”. En: Cañestro Donoso, Alejandro (coord.), Svmma stvdiorum scvlptoricae: In memoriam Dr. Lorenz Hernández Guardiola. Diputación Provincial de Alicante, Instituto Alicantino de Cultura Juan Gil-Albert, pp. 565-582

Fernández de Navarrete, Martín (1870): Colección de documentos inéditos para la Historia de España, LV, Madrid: Imprenta de la viuda de Calero.

Fernández Peña, María Rosa (2006): "La Santa, Pontificia y Real Hermandad del Refugio y Piedad de Madrid en la iglesia de San Antonio de los Alemanes. Una institución de caridad dentro de un recinto de arte". En: Campos y Fernández de Sevilla, Francisco (coord.): La Iglesia española y las instituciones de caridad. Madrid: Ediciones Escurialenses, pp. 883-898.

Gascón de Torquemada, Jerónimo (1991): Gaçeta y nuevas de la corte de España desde el año 1600 en adelante [1646]. Madrid: Real Academia Matritense de Heráldica y Genealogía.

Gómez Laínez, Mariola (ed.) (2015): Santa, Pontificia y Real Hermandad del Refugio y Piedad de Madrid: la iglesia de San Antonio de los Alemanes: IV centenario. Madrid: Santa, Pontificia y Real Hermandad del Refugio y Piedad.

Lleó Cañal, Vicente (2017): La Casa de Pilatos: biografia de un palacio sevillano. Sevilla: Universidad de Sevilla.

Moralejo Ortega, Macarena (2016): La Hermandad del Refugio y Piedad de Madrid (1615-2015): cuatro siglos de historia. Madrid: Fundación Universitaria Española.

Pacheco, Francisco (1990): Arte de la Pintura [1649]. Bassegoda i Hugas, Bonaventura (ed.). Madrid: Cátedra.

Pajarón Sotomayor, María (1977): San Antonio de los Alemanes. Madrid: Real Hermandad del Refugio.

Parrino, Domenico Antonio (1692): Teatro eroico e politico de' governi de' viceré del regno di Napoli, vol. 2. Nápoles: Nuova stampa del Parrino e del Mutii.

Pascual Chenel, Álvaro / Rodríguez Rebollo, Ángel (2015): Vicente Carducho. Dibujos. Catálogo razonado. Madrid: Biblioteca Nacional de España.

Pérez Preciado, José Juan (2016): “Art Aficionados at Court”. En: Andrews, Jean / Noble Wood, Oliver / Roe, Jeremy (eds.): On Art and Painting: Vicente Carducho and Baroque Spain. University of Wales Press, pp. 119-147.

Reula Baquero, Pedro (2019): El camarín del desengaño. Juan de Espina, coleccionista y curioso del siglo XVII. Madrid. Centro de Estudios Europa Hispánica.

Schütze, Sebastian / Willette, Thomas (1992): Massimo Stanzione. L'opera completa. Electa: Nápoles.

Signorini, Anna Eleanor (2014): "Massimo Stanzione (1585-1656) nella Galleria Corsini di Roma: due tele restaurate a confronto". Arte Cristiana, CII, 885, pp. 455-458.

Tepa, Conde de (1995): Breve historia de la Santa, Pontificia y Real Hermandad del Refugio y Piedad de Madrid. Madrid: Hermandad del Refugio.

Fecha de recepción: 26-XI-2020

Fecha de aceptación: 15-III-2021 